\title{
A thermo-mechanical model for the catastrophic collapse of large landslides
}

Francesco Cecinato $^{1, a}$, Antonis Zervos ${ }^{1}$, and Emmanuil Veveakis ${ }^{2}$

${ }^{1}$ University of Southampton, School of Civil Engineering and the Environment, SO171BJ Southampton (UK).

${ }^{2}$ National Technical University of Athens, Department of Applied Mathematics and Physics, Iroon Politexniou 5, 15773 Athens (Greece).

In memoriam of Professor Ioannis Vardoulakis.

${ }^{a}$ Corresponding Author. Email: francesco.cecinato@gmail.com 


\begin{abstract}
In this work, a new thermo-mechanical model is developed, applicable to largescale, deep-seated landslides consisting of a coherent mass sliding on a thin clayey layer. The considered time window is that of catastrophic acceleration, starting at incipient failure and ending when the acquired displacement and velocity are such that the sliding material begins to break up into pieces. The model accounts for temperature rise in the slip zone due to the heat produced by friction, leading to water expansion, thermoplastic collapse of the soil skeleton and subsequent increase of pore water pressure. The model incorporates the processes of heat production and diffusion, pore pressure generation and diffusion, and an advanced constitutive law for the thermo-mechanical behavior of soil. An analysis of the Vajont landslide is presented as an example. A sensitivity analysis shows that friction softening is the mechanism most affecting the timescale of the final collapse of a slide, but also that the mechanism of thermal pressurization alone can cause a comparably catastrophic dynamic evolution. It is also shown that, all other factors being equal, thermomechanical collapse will cause thicker slides to accelerate faster than shallow ones.
\end{abstract}

Keywords: Thermal pressurization, constitutive modeling, landslide dynamics, numerical analysis, thermo-mechanics.

\title{
1. Introduction
}

The mechanics of the final collapse of large slope failures are still poorly understood, and have constituted a challenge to physicists, geologists and engineers over the last 40 years. The reasons why some observed catastrophic landslides moved so fast and so far cannot always be explained using standard analyses. Recent examples of such slope failures include the disastrous 1963 Vajont slide that occurred in northern Italy and claimed more than 2,000 victims, the Sale Mountain compound rockslide that occurred in China in 1985, and the 1999 earthquake-triggered Jiufengershan slide in Taiwan, which buried 39 people.

Frictional heating of the slip zone has long been considered a possible explanation for the unusually high velocities and long run-outs of some large-scale landslides [1-3]. Pore pressure in soils increases with temperature due to thermal expansion and the eventual thermal collapse of the skeleton $[4,5,6]$, especially under 
conditions of slow or no drainage, like the ones occurring in the rapidly deforming slip zone of a landslide. Furthermore, heating reduces the soil's apparent overconsolidation ratio, shrinks its elastic domain and lowers its peak stress ratio [6, 7]. Thermal-friction softening (i.e. decrease of the friction angle) is also possible [8, 9]. These processes lead to declining shear resistance at the slip zone, causing the sliding mass to accelerate and potentially making the difference between a relatively low-impact event and a catastrophic one.

While Habib [1] had theorized vaporization of pore water and the subsequent creation of a gas cushion to justify the loss of shear strength in the slip plane of some large landslides, Voight and Faust [3] proposed that substantial strength loss would happen due to a mere rise in pore water pressure, without the need for water to change phase. More recently, also Chang et al. [10] presented a quantitative analysis of earthquake-triggered landsliding by resorting to thermo-mechanics, based on a simplified block-on-slope model to calculate the average loss of strength due to pressurization and the subsequent velocity evolution of the slide. The first comprehensive landslide model accounting for frictional heating and thermal pressurization in the slip plane of a uniform slope was presented by Vardoulakis [11, 12]. However, the specialized constitutive law used for the soil restricts its applicability. In particular, it cannot capture the full range of temperature-dependent soil behavior observed experimentally, and it cannot be easily generalized to include the behavior of the soil prior to failure, or to two- or three-dimensional problems.

In this work we adopt a more general and more realistic constitutive assumption for the soil, applicable to a wider range of soils. The landslide model presented takes into account heat generation and diffusion, pore pressure generation and dissipation, and the temperature dependence of the mechanical behavior of soil. More specifically, a thermo-plastic Modified Cam Clay constitutive framework is adopted for the soil, in which different types of softening mechanisms, namely strain-, strain rate-, thermaland thermal friction- softening, can be accommodated. An additional development is that, as a result, the parameter quantifying pore pressure build-up due to temperature increase, i.e. the pressurization coefficient, is no longer independent as in $[11,12]$ but can be determined in terms of other material parameters and the value of state variables. The well-documented large-scale landslide of Vajont is analysed as an example and some further numerical analysis is performed to assess the sensitivity of the model to the friction softening and pressurization mechanisms. 
In the following, we present in Section 2 a thermo-mechanical constitutive model able to capture the main features of the thermal behavior of soils, while in Section 3 the formulation and implementation of the modified landslide model is discussed. Section 4 deals with the analysis of the Vajont case history as an example of rotational slide collapse, where the impact of different friction softening scenarios in the dynamic evolution of the slide is explored. Finally, in Section 5 a sensitivity analysis is performed to investigate the impact of thermal pressurization in the dynamical evolution of planar slides. Some conclusions are drawn in Section 6.

\section{Constitutive modeling of the basal material}

\subsection{Thermo-plastic behavior of soil}

Temperature has been shown to influence the behavior of clays by causing volume variations of the free water and by changing the adsorption forces in the structural water [13]. Such effects are reflected in volumetric strains caused by heating which are mainly reversible and dilative if the soil is over-consolidated, and irreversible and contractive if the soil is normally-consolidated [6, 9]. Another typical feature of clays is thermal softening, i.e. a reduction of the size of the elasticity domain of the soil as temperature increases [7]. Several experimental studies have been conducted on the effects of temperature in soils, with particular reference to clays, aiming at the development of constitutive models relevant to thermomechanical loading paths.

The first theoretical model on the thermal response of soils was proposed by Campanella and Mitchell [14], which formed the basis for several subsequent constitutive studies; notably Hueckel and Borsetto [15] described the thermoplasticity of saturated soils and shales, and more recently Laloui and Cekerevac [7] proposed a model to describe the volumetric response of clay to heating, which was then extended to a multi-mechanism framework by Laloui et al. [9]. Other authors, such as Sultan et al. [16] and Cui et al. [17] developed more specialized models aiming to better reproduce the effects of over-consolidation ratio on the thermal volumetric behavior of clays.

Below, we describe the development of a constitutive model able to capture the main features outlined above in the context of a rapidly deforming clayey shearband subject to frictional heating. Given the overall complexity of the shearband problem (Section 4), it is desirable for the constitutive law to contain the least possible number 
of material parameters and to be easy to generalize. The constitutive framework of Laloui and Cekerevac [7] and Laloui et al. [9], due to the simplicity of its formulation, is taken as a suitable basis for this development.

\subsubsection{Problem formulation}

The response of clay to heating is hereafter approached within the framework of critical state soil mechanics [18], through the rewriting of the four classic 'ingredients' of elasto-plasticity [19]: the elasticity law, describing the recoverable deformations; the yield condition, describing the boundary of the region in stress space within which it is possible to describe the deformation as elastic and recoverable; the hardening rule, describing the way in which the magnitude of plastic deformation is linked to the evolution of the yield locus; and the plastic potential (flow rule), to specify the direction of plastic deformation.

The Modified Cam Clay model [20] is adopted as the basis of constitutive thermo-plasticity, as this is a widely used model with clear advantages when it comes to numerical implementation. Accordingly, the yield surface is expressed in terms of the mean effective stress $p^{\prime}$ and the deviatoric stress $q$ and associated plastic flow flow is assumed.

The thermal softening/hardening features of the volumetric behavior of soil are described by employing the hardening rule proposed by Laloui and Cekerevac [7] where the apparent preconsolidation stress $\sigma_{c}^{\prime}$, corresponding to the intersection of the yield surface with the mean effective stress axis, is allowed to vary with temperature following an exponential law:

$$
\sigma_{c}^{\prime}=\sigma_{c 0}^{\prime} \exp \left(\tilde{\beta} \varepsilon_{v}^{p}\right)\left[1-\gamma \log \left(\theta / \theta_{r e f}\right)\right]
$$

In the above, $\sigma_{c 0}^{\prime}$ is the isothermal value of the preconsolidation stress, $\tilde{\beta}$ the plastic compressibility, $\varepsilon_{v}^{p}$ the accumulated volumetric plastic strain, $\gamma$ a material parameter representing the rate of softening and $\theta$ and $\theta_{r e f}$ the current and reference values of temperature respectively. Equation (1) describes the experimentally observed expansion of the elastic domain with increasing volumetric plastic strain and contraction with increasing temperature. 
Another feature that has been observed in some clays is the dependence on temperature of the friction angle at critical state $\phi_{c s}^{\prime}$. This is an issue on which there is no clear consensus in the literature, as both the existence of a temperature effect on $\phi_{c s}^{\prime}$ and its nature appear to be heavily material-dependent. For some clays $\phi_{c s}^{\prime}$ may remain virtually constant as temperature increases [21], for others it will linearly decrease [9], while there are even cases where a slight increase of $\phi_{c s}^{\prime}$ with increasing temperature is observed [13]. In the context of the thermo-mechanics of a landslide, a possible decrease of $\phi_{c s}^{\prime}$ with temperature (i.e. thermal-friction softening) may be an important mechanism contributing to the further destabilization of the sliding mass.

To allow for the possibility of thermal-friction softening, we adopt the linear law proposed by Laloui et al. [9], describing the decrease of the critical state parameter with increasing temperature:

$$
M=M_{r e f}-\tilde{g}\left(\theta-\theta_{r e f}\right)
$$

where $M_{r e f}$ is the value of critical state parameter at the reference temperature $\theta_{\text {ref }}$, and $\tilde{g}$ represents the rate of thermal friction softening.

In this framework, the temperature-dependent Modified Cam Clay yield surface is represented as a function of mean effective stress $p^{\prime}$, deviatoric stress $q$ and temperature $\theta$ (Figure 1), as:

$$
f=q^{2}-M^{2} p^{\prime}\left(\sigma_{c}^{\prime}-p^{\prime}\right)
$$

where $\sigma_{c}^{\prime}$ is in general expressed by (1), and $M$ is expressed as (2).

In the next sections, we give details of how the thermo-elastic and thermo-plastic components of the deformation can be calculated.

\subsubsection{Thermo-elasticity}

The thermo-elastic relationships, linking the stress increment of the material to the increments of recoverable strain and temperature, can be derived from standard continuum mechanics (see Appendix A): 


$$
\dot{\boldsymbol{\sigma}}=\mathbf{D}^{m e} \dot{\boldsymbol{\varepsilon}}^{m e}+\mathbf{D}^{t e} \dot{\theta}
$$

where $\boldsymbol{\sigma}$ is the stress tensor, $\mathbf{D}^{m e}$ is the stress-dependent elasticity tensor, $\mathbf{D}^{t e}=-$ $\beta_{s} K \delta_{i j}$ the thermal tensor, $K$ the bulk modulus, $\beta_{s}$ the volumetric thermal expansion coefficient, $\boldsymbol{\delta}_{i j}$ the unit matrix, $\boldsymbol{\varepsilon}$ the strain tensor and $\theta$ the temperature.

\subsubsection{Thermo-plasticity}

If the stress path intersects the yield surface, the soil will exhibit plastic yield and thus develop irrecoverable deformations. At plastic loading states, in order to find the stress increment associated with a temperature and strain increment, it is necessary to solve a system of two rate equations. Employing standard techniques, these equations can be written in terms of total strain and temperature rates as (Appendix A):

$$
\left\{\begin{array}{l}
\dot{\boldsymbol{\sigma}}=\mathbf{D}^{m e p} \dot{\boldsymbol{\varepsilon}}+\mathbf{D}^{t e p} \dot{\theta} \\
\dot{\sigma}_{c}^{\prime}=A \cdot \dot{\theta}+B \cdot \dot{\lambda}
\end{array}\right.
$$

where $\sigma_{c}^{\prime}$ is the preconsolidation stress, and $A$ and $B$ two coefficients that are functions of temperature, the plastic volumetric strain and other soil parameters. In the above, $\dot{\lambda}$ is the plastic multiplier, which can be determined from the consistency condition $d f=0$ (Appendix A):

$$
\dot{\lambda}=\frac{f_{\boldsymbol{\sigma}} \mathbf{D}^{m e} \dot{\boldsymbol{\varepsilon}}+\left(f_{\theta}+2 \mathbf{D}^{t e} f_{\boldsymbol{\sigma}}\right) \dot{\theta}}{f_{\boldsymbol{\sigma}} \mathbf{D}^{m e} f_{\boldsymbol{\sigma}}-f_{\varepsilon_{v}^{p}} f_{p}}
$$

where $f=f\left(\sigma_{i j}, \varepsilon_{v}^{p}, \theta\right)$ the yield function of equation (3). Partial derivatives of the yield function with respect to other model variables are denoted by subscripts.

\subsection{Thermal pressurization mechanism}

Thermal pressurization due to frictional heating has been studied in a number of different contexts, including thermal weakening of rock faults during co-seismic slip [22], thermal collapse of clay materials in fault zones [13, 23] or slip zones of rapid landslides $[11,12]$. Experimental evidence of thermal pressurization in both rocks and soils is also available $[14,16,24,25,26]$. 
The key parameter governing thermal pressurization is the pressurization coefficient $\lambda_{m}$, defined as the pore pressure increase due to a unit temperature increase in undrained conditions: $\lambda_{m}=\partial u / \partial \theta$, where $u$ the pore pressure. Its value depends on the material, the temperature and the stress level. Different average values for $\lambda_{m}$ have been proposed, ranging two orders of magnitude. For clay, Campanella and Mitchell [14] found $\lambda_{m}=0.01 \mathrm{MPa} /{ }^{\circ} \mathrm{C}$, Vardoulakis [12] proposed $\lambda_{m}=0.06 \mathrm{MPa} /{ }^{\circ} \mathrm{C}$ while Sulem et al. [13] suggested $\lambda_{m}=0.1 \mathrm{MPa} /{ }^{\circ} \mathrm{C}$. For sandstone, Campanella and Mitchell [14] proposed $\lambda_{m}=0.05 \mathrm{MPa} /{ }^{\circ} \mathrm{C}$ while Rice [22] estimated $\lambda_{m}=0.92 \mathrm{MPa} /{ }^{\circ} \mathrm{C}$ for a $7 \mathrm{~km}$ deep fault with intact walls.

There is a substantial difference in the thermal pressurization mechanisms between clay and rock materials: while rocks essentially behave elastically and $\lambda_{m}$ is found to depend on thermo-elastic coefficients only, clays may undergo plastic straining upon thermal loading, giving rise to an additional dependence of $\lambda_{m}$ on the soil's thermo-plastic contraction coefficient. It has been found experimentally (e.g., $[6,9])$ that normally-consolidated clays in general, when heated under drained conditions exhibit a net volume reduction. This is due to an internal mechanism of micro-structural collapse, which in turn is due to changes in water adsorption by the clay particles and changes in the equilibrium between attractive and repulsive electrostatic forces between ions forming the double layer [14].

Many authors (e.g., [5, 24, 26, 27]) reported that while normally-consolidated clays exhibit plastic contraction upon heating, over-consolidated clays tend to behave elastically and expand at the initial stages of heating, subsequently showing plastic contraction at higher temperatures. For this reason, experimental thermal loading paths are usually plotted for different over-consolidation ratios (OCR), where OCR is the ratio between the soil's preconsolidation stress and the current mean effective stress at the start of testing. The attainment of a 'critical temperature' at which plastic contraction starts in over-consolidated soils is evident in the change in slope of some of the plots describing isotropic heating tests at constant confining stress, when the soil's volumetric behavior changes from dilative to contractive (e.g., see Figure 8 of [7]).

Based on the available experimental evidence and theoretical considerations from mixtures theory, Vardoulakis [12] expressed the coefficient $\lambda_{m}$ for a clayey shearband 
in terms of the soil's thermo-plastic contraction coefficient $\alpha_{c}^{p}$ and the compressibility coefficient $c$, as

$$
\lambda_{m}= \begin{cases}0 & \text { if } \theta \leq \theta_{\text {crit }} \\ \frac{-\alpha_{c}^{p}}{c} & \text { if } \theta>\theta_{\text {crit }}\end{cases}
$$

where $\theta_{\text {crit }}$ represents the critical temperature at which plastic collapse of the soil skeleton starts. In [12] an expression giving $\theta_{c r i t}$ as a function of the soil's OCR was proposed based on experimental data obtained in [24].

Within the framework of the constitutive model presented in Section 2.1, the soil's thermal behavior discussed above exhibits some typical features: in purely elastic conditions the volumetric response of clay to heating is reversible and depends only on the expansion coefficient $\beta_{s}$; in elasto-plastic conditions, the volumetric response is governed by the flow rule (Appendix A). In this context, the initial OCR is not a parameter of the problem, but merely an indicator of whether the state of the soil at the start of loading is elastic or plastic: for a normally-consolidated soil (i.e. $\mathrm{OCR}=1$ ), further thermal or mechanical loading causes plastic flow, while for an overconsolidated soil it initially causes elastic (reversible) strains until the stress state reaches the yield surface. Within this framework the thermo-plastic contraction coefficient $\alpha_{c}^{p}$ and the pressurization coefficient $\lambda_{m}$ can be calculated directly from the constitutive model as functions of temperature, void ratio and the soil constants.

By definition, the thermal expansion (or contraction) coefficient $\alpha_{c}$ in a straintemperature constitutive relationship is the factor pre-multiplying the temperature rate:

$$
\dot{\varepsilon}^{t e p}=\frac{\partial \varepsilon}{\partial \theta} \frac{d \theta}{d t}=\alpha_{c} \frac{d \theta}{d t}
$$

where $\dot{\varepsilon}^{\text {tep }}$ is the thermal contribution to the total thermo-mechanical strain rate

$$
\dot{\varepsilon}_{\text {tot }}=\dot{\varepsilon}^{t e p}+\dot{\varepsilon}^{m e p},
$$


and $\dot{\varepsilon}^{\text {mep }}$ represents the mechanical contribution.

In the elastic regime, the coefficient $\alpha_{c}=\beta_{s}$ is identified from the expression for the elastic volumetric strain rate, as in equation (4), and can be considered either constant, at first approximation, or pressure- and temperature-dependent (e.g. [7]). Similarly, during plastic yielding the thermo-plastic contraction coefficient $\alpha_{c}^{p}$ (denoting the thermal contribution to the global volumetric strain rate) coincides with the factor pre-multiplying the temperature rate in the plastic flow expression. Accordingly, by elaborating upon the flow relationship at isotropic loading conditions, we obtain (Appendix B):

$$
\alpha_{c}^{p}(\theta)=\frac{\lambda-\kappa}{\lambda}\left\{\frac{\gamma \kappa}{(1+\mathrm{e}) \theta\left[1-\gamma \log \left(\theta / \theta_{r e f}\right)\right]}-2 \beta_{s}\right\}
$$

where $\lambda$ and $\kappa$ are the slope of the normal-compression line and the unloadingreloading line of the soil respectively, and $e$ is the void ratio. The thermo-plastic contraction coefficient $\alpha_{c}^{t p}$ must be negative to be physically meaningful, and shows dependency on the current temperature level and some constant soil parameters, whose values are discussed in Section 4.1.

Equation (10) overcomes the concept of critical temperature introduced in Vardoulakis [12]. Thermal dependency of coefficient $\alpha_{c}^{p}$ allows for a gradual soil skeleton collapse, and the temperature-dependent pressurization coefficient is expressed for all values of temperature as

$$
\lambda_{m}=\frac{-\alpha_{c}^{p}(\theta)}{c}
$$

Hence the constitutive model accounts for thermoplastic yielding as soon as a temperature increase occurs, regardless of its magnitude, provided that the stress state lies on the yield envelope.

The above basic considerations for the interpretation of the thermal volumetric behavior of soils incidentally provide a different way of explaining the occurrence of 
excess pore pressures within the rapidly deforming shearband at the base of a landslide. Isotropic thermoplastic contraction of the soil measures how much the soil volume would collapse if this were possible. However, as will be discussed in Section 3.1, the soil within the shearband is assumed to be at critical state and thus its volume cannot change. Excess pore pressures will then develop due to the inability of the thermally collapsing skeleton to contract.

The calculation of the pressurization coefficient according to equation (11) is completed once the oedometric compressibility coefficient $\mathrm{c}$ is determined [12]. This can be expressed as (Appendix C):

$$
c=\left(\frac{e}{1+e}\right) c_{w}+\frac{\kappa(1+v)}{3 p_{0}^{\prime}(1-v)(1+e)}
$$

where $c_{w}$ is the compressibility of water, $p_{0}^{\prime}$ the initial mean effective stress acting on the shearband and $v$ the Poisson ratio of the soil.

\section{Thermo-mechanical landslide model}

The geometry of a considered landslide is divided into two regions consisting of (1) the shear-band, which is a thin zone where all deformation is localized and which is embedded in an otherwise thicker soil layer, and (2) the overburden, which moves as a rigid block. The thickness of the shearband may be empirically related to the mean grain size of the geomaterial $[12,28]$; it is assumed a constant parameter of the problem at hand. The landslide model consists of a set of coupled partial differential equations describing the time evolution of temperature and pore pressure within the shear-band, while the shear-band velocity profile is assumed linear [29]. These equations are coupled to a global dynamic equation describing the velocity evolution of the rigid block through the value of velocity at the shearband-block interface (Figure 2). The equations are presented below.

It should be noted that the model presented below is expressed in terms of small deformations. Given the amount of shearing that takes place in the shearband and the amount of displacement of the sliding mass, a formulation accounting for large deformations would be more accurate. However, given the uncertainties involved in the determination of the field conditions and the material parameters, accounting for large deformations would complicate the problem without offering better insights on 
the underlying mechanics governing the system. In addition, a small deformation formulation is more consistent with the way that experimental data are routinely interpreted and material parameters reported; it also has the added benefit of being easier to deal with numerically

\subsection{Governing equations for the shearband}

The considered analysis starts at incipient failure, thus we can assume that the soil within the shearband has already undergone adequate shearing, e.g. due to preceding seepage- or earthquake-driven movements, to have reached critical state. This implies continuing plastic shearing at constant specific volume, and provides a direct relationship between the deviatoric stress $q$ and the apparent preconsolidation stress $\sigma_{c}^{\prime}$ of the soil within the shearband, through the critical state parameter $M$ :

$$
q=\frac{M \sigma_{c}^{\prime}}{2}
$$

Plane strain conditions are assumed; with reference to Figure 2, the direction of zero strain is along the $y$ axis, while the $x$ axis points in the direction of movement and the $z$ axis is taken perpendicular to it. A linear profile of velocity within the shearband is assumed [29], i.e.

$$
v_{x}=v_{d}(t) \frac{z}{d}
$$

where $d$ is the shearband thickness (cf. Figure 2). It is further assumed that the bulk of the slide moves as a rigid body with a speed $v_{d}(t)$, which constitutes the coupling variable between the two shearband equations and the dynamics of the slide. Velocity and acceleration components along the $\mathrm{z}$ axis are considered negligible. We finally remark that the small thickness of the band, compared to the slide dimensions, allows the formulation of the problem in one dimension [12]: all variations in the direction of sliding are neglected, i.e. $\partial u / \partial x=\partial \theta / \partial x=0$, so that temperature and pore pressure changes will be assumed along the $z$-direction only.

\subsubsection{Heat equation}


The first equation of the model is derived from the local form of the energy balance law within the shearband [12], and describes the 1-D time evolution of temperature $\theta$ within the shearband:

$$
\frac{\partial \theta}{\partial t}=k_{m} \frac{\partial^{2} \theta}{\partial z^{2}}+\frac{D}{C_{f}}
$$

The first term on the right-hand side is a heat diffusion term, where $k_{m}$ is a constant thermal diffusivity coefficient, and the second term is a heat generation one, where $D$ is the rate of dissipated energy. Finally, $C_{f}=j(\rho C)_{m}$ is a thermal constant, where $j=4.2 \mathrm{~J} / \mathrm{cal}$ is the mechanical equivalent of heat and $(\rho C)_{m}$ the product of the density and the specific heat of the soil-water mixture.

The rate of dissipated energy is taken equal to the plastic work, expressed as $D \approx \tau \dot{\gamma}^{p}$, where $\tau$ is the shear stress and $\dot{\gamma}^{p}$ the plastic shear strain, and can be rewritten for the above thermo-plastic constitutive model of Section 2 as (see Appendix D)

$$
D=\frac{1}{2} \dot{\lambda}\left(M \sigma_{c}^{\prime}\right)^{2}
$$

where $\dot{\lambda}$ is the plastic multiplier defined in equation (6). It is shown in Appendix E that, at critical state, $\dot{\lambda}$ can be expressed as

$$
\dot{\lambda}=F_{1} \frac{\partial \theta}{\partial t}+F_{2} \frac{\partial v_{x}}{\partial z}
$$

where $F_{1}(\theta, u)$ and $F_{2}(\theta, u)$ are temperature- and pore pressure-dependent coefficients and $v_{x}$ is the velocity profile within the shearband. Also, the apparent preconsolidation stress $\sigma_{c}^{\prime}$ depends on temperature according to the hardening law of equation (1), and is uniquely related at critical state to the mean effective stress $p^{\prime}$ as $\sigma_{c}^{\prime}=2 p^{\prime}$. According to the effective stress principle, $p^{\prime}$ decreases as excess pore pressure builds up: 


$$
p^{\prime}=p_{0}^{\prime}-u(t)
$$

In critical state soil mechanics the parameter $M$ is constant, and depends on the soil's friction angle at critical state. On the other hand, prolonged and fast shearing along a defined failure plane often brings about a drop in the friction angle of clays on that plane, due to alignment of the clay particles parallel to the direction of shearing, until a 'residual state' is reached (e.g., [30, 31]). We choose here to adjust the value of $M$ in order to approximate such a residual state behavior under constant volume conditions, by accounting for the reduction of the friction angle with displacement and velocity. This can be done following the hyperbolic strain- and strain-rate softening law proposed by Vardoulakis ([12], equation (5)), which depends on two parameters, $a_{1}$ and $a_{2}$, defining the rates of static and dynamic material softening respectively. Furthermore, we allow for possible thermal-friction softening behavior as in Section 2.1.1. Therefore in the general case the critical state parameter $M$, which can be uniquely related to the friction angle at critical state $\varphi_{c s}^{\prime}$, depends on strain, strain-rate and temperature [32], as

$$
M(\gamma, \dot{\gamma}, \theta)=\hat{M}(\gamma, \dot{\gamma})-\tilde{g}\left(\theta-\theta_{r e f}\right)
$$

where $\hat{M}(\gamma, \dot{\gamma})$ follows the static and dynamic friction-softening law of [12] as detailed in Appendix F.

A demonstration of the above constitutive assumptions is given in Figure 3, which shows a typical (effective) stress path of a material point within the shearband during catastrophic sliding. The contributions of the different mechanisms affecting the stress state are drawn separately, although they all occur at the same time. In a generic time interval $\Delta t$ during sliding, the stress state, locked to the top of the yield locus due to the assumption of critical state, follows the path 1-3. From state 1 to 2 , thermal softening occurs while excess pore pressures develop, causing the yield locus to shrink consistently with the hardening law and the effective stress principle. From 3 to 4 frictional softening occurs, causing a decrease in the slope of the CSL and a consequent further change in stress. 
Substituting the above into the heat equation (15) (Appendix E) leads to

$$
\frac{\partial \theta}{\partial t}=D_{i} \frac{\partial^{2} \theta}{\partial z^{2}}+F_{i} \frac{v_{d}(t)}{d}
$$

where $v_{d}(t)$ is the velocity at the upper boundary of the shearband, also corresponding to the sliding velocity of the rigid block (cf. Figure 2). Coefficients $D_{i}(\theta, u, \gamma, \dot{\gamma})$ and $F_{i}(\theta, u, \gamma, \dot{\gamma})$ depend on pore pressure $u$, temperature $\theta$ and, if the soil exhibits friction-softening, also on the shear strain $\gamma$ and strain rate $\dot{\gamma}$.

\subsubsection{Well-posedness of the heat equation}

Equation (20) is a diffusion-generation equation for the temperature where, unlike Vardoulakis [12], the diffusivity coefficient varies non-linearly with temperature and pore pressure as (Appendix E)

$$
D_{i}=\frac{k_{m}}{1-\frac{\left[M(\theta, \gamma, \dot{\gamma}) \sigma_{c}^{\prime}(\theta)\right]^{2}}{2 C_{f}} F_{1}(\theta, u)}
$$

As the diffusivity $D_{i}$ is not constant, it may, theoretically at least, assume negative values. This however would imply mathematical ill-posedness of the equation and inability to solve it. To ensure that the problem remains well-posed, the sign of the coefficient $D_{i}$ was calculated for a wide range of parameter values within the temperature range $0<\theta<1000{ }^{\circ} \mathrm{C}$. Diffusivity proved to be always positive for all parameter values examined, showing negligible variation of the order of $0.01 \%$ around the initial value of soil thermal diffusivity $k_{m}=1.45^{*} 10^{-7} \mathrm{~m}^{2} / \mathrm{sec}$. The parameter ranges used were: $10^{-8} \leq \tilde{g} \leq 10^{-1}$ for the thermal sensitivity, $0.25 \leq M_{\text {ref }} \leq 0.85$ and $0.1 \leq \sigma_{m}^{\prime} \leq 10 \mathrm{MPa}$ for the critical state parameter and the preconsolidation stress at ambient temperature respectively, $5 \leq \tilde{\beta} \leq 20$ for the plastic compressibility, $10^{-}$ ${ }^{3} \leq \kappa \leq 5 \times 10^{-2}$ for the slope of the elastic re-compression line, $0.15 \leq v \leq 0.45$ for the Poisson's ratio, $0.2 \leq e \leq 1.5$ for the void ratio and $0.005 \leq \gamma \leq 0.5$ for the thermal softening parameter $\gamma$.

\subsubsection{Pore pressure equation}


The pore pressure equation, derived in [12] from mass balance considerations and Darcy's law, describes the time evolution of excess pore pressures within the shearband and its surroundings:

$$
\frac{\partial u}{\partial t}=\frac{\partial}{\partial z}\left(c_{v} \frac{\partial u}{\partial z}\right)+\lambda_{m} \frac{\partial \theta}{\partial t}
$$

In the above, $\lambda_{m}$ is the temperature-dependent pressurization coefficient and $c_{v}$ is the consolidation coefficient. The former, as explained in Section 2.2, stems directly from the thermo-plasticity equations; the latter is a function of soil compressibility and soil permeability, expressed as

$$
c_{v}=\frac{k_{w}}{g \rho_{w} c}
$$

where $c$ is the soil compressibility, $g$ the acceleration of gravity, $\rho_{w}$ the porefluid density and $k_{w}$ is Darcy's permeability coefficient, which is an increasing function of porosity and fluid density and inversely proportional to the viscosity of the fluid. Experimental results [33-35] showed that $c_{v}$ for clay is expected to be a weakly increasing function of temperature, exhibiting a variation of much less than an order of magnitude for a $50^{\circ} \mathrm{C}$ increase. This is due to two antagonistic effects: Darcy permeability increases with temperature, as a consequence of the thermal decrease of viscosity of the pore fluid, but this effect is compensated by a concurrent decrease of the porosity. As a consequence, the thermal variation of the consolidation coefficient is not significant in the current context. We will consider the consolidation coefficient constant, with an average value $\bar{c}_{v}$, calculated through equation (23) in terms of the average permeability and compressibility of the soil. This enables us to re-write the pore pressure equation in the following final form:

$$
\frac{\partial u}{\partial t}=\bar{c}_{v} \frac{\partial^{2} u}{\partial z^{2}}+\lambda_{m} \frac{\partial \theta}{\partial t}
$$

\subsection{Dynamic equation of the sliding mass}


To describe the time evolution of the landslide velocity a dynamical equation is needed, which will be coupled with the two shearband equations presented above. Two representative scenarios have been identified as relevant to the analysis of largescale landslides: planar sliding and rotational sliding. The former case corresponds to the so-called infinite slope approximation, and is appropriate for translational landslides in which the rupture surface can be assumed with reasonable approximation as parallel to the surface of the slope; the latter is appropriate for deep-seated landslide cases in which the slip surface can be approximated as circular. The two scenarios are analyzed separately below.

\subsubsection{Planar slides}

Within the framework of an infinite slope geometry, shown in Figure 4, the slope is assumed uniform and of unlimited extent. The slip plane is considered parallel to the surface of the slope at depth $H$. A unit length of slope is considered in the analysis and, for a given geometry, gravity and seepage forces determine the safety factor in static analyses, or the acceleration in post-failure, dynamic analyses.

From considerations of dynamic equilibrium of the unit length block of Figure 4 we may derive the dynamical equation for the infinite slope:

$$
\frac{d v_{d}}{d t}=g\left[\sin \beta-\frac{\tau_{z x}(t)}{\gamma_{s} H}\right] .
$$

In the above, $v_{d}$ is the velocity of the block, $g$ the acceleration of gravity, $\beta$ the slope angle, $\gamma_{s}$ the unit weight of the soil and $\tau_{z x}(t)$ the shear stress acting on the shearband. The latter, together with the block velocity, provide the coupling between the shearband constitutive model and the dynamical equation, and can be expressed according to a conventional Mohr-Coulomb frictional law as:

$$
\tau_{z x}(t)=\sigma_{n}^{\prime}(t) \cdot \tan \left(\varphi_{c s}^{\prime}\right)
$$

where $\varphi_{c s}^{\prime}(t)=\varphi_{c s}^{\prime}(\gamma, \dot{\gamma}, \theta)$ is the (potentially softening with strain, strain rate and temperature) friction angle and $\sigma_{n}^{\prime}(t)=\sigma_{n 0}^{\prime}-u(t)$ the normal effective stress. It is 
useful to write $\sigma_{n}^{\prime}$ in terms of the mean effective stress $p^{\prime}$; it is shown in Appendix C that, under the simplifying assumption that $\sigma_{x x}^{\prime}=\sigma_{y y}^{\prime}$,

$$
\sigma_{n}^{\prime}=3\left(\frac{1-v}{1+v}\right) p^{\prime}
$$

where the current mean effective stress $p^{\prime}$ is expressed by equation (18).

The description of the dynamic evolution of the slide is then determined by integrating the system of coupled equations (25), (20) and (24) with appropriate initial and boundary conditions.

\subsubsection{Rotational slides}

To examine the balance of forces in a rotational landslide, where the soil mass is assumed to rotate about the center of a previously identified failure circle, it is necessary to know the value of both the normal stress and the pore pressure acting at each point on the slip surface [36]. A simplified procedure may be adopted for homogeneous soils using the friction circle method [37], in which the friction angle is assumed constant along the whole slip circle and an assumption is made about the distribution of normal stress along the slip surface.

In the context of a dynamic analysis of rotational landslides, the balance of angular momentum for the rotating rigid body may be written in terms of the geometry of a typical cross-section of the slope, the soil properties and the net driving moment T:

$$
\dot{\omega}=\frac{T}{\rho I_{p}}
$$

where $\dot{\omega}$ is the angular acceleration, $\rho$ is the soil density and $I_{p}$ the polar moment of inertia of the rotating mass with respect to the center of the failure circle. Furthermore $T=T_{D}-T_{R}$, where the total driving moment $T_{D}$ is derived from the resultant driving force and the resisting moment $T_{R}$ depends on the soil's friction angle as well as on the pore water pressure at the base of the slide. 
Vardoulakis [12] proposed a dynamical analysis with the above friction circle method, with the additional simplifying assumption that the stress and the pore pressure at the base of the slide are constant and equal to their respective mean values. Under these assumptions the acceleration of the slide is eventually expressed as:

$$
\frac{d v_{d}}{d t}=R \omega_{0}^{2}\left(A\left(\varphi_{c s}^{\prime}\right)+\frac{u_{d}(t)}{p_{c}\left(\varphi_{c s}^{\prime}\right)}\right)
$$

where $R$ is the radius of the failure circle, $\omega_{0}$ is a constant with dimensions of angular velocity, $\mathrm{A}$ is a dimensionless acceleration factor and $p_{c}$ is a parameter with the dimensions of pressure [12]. Equation (29) may be adopted to interpret the dynamics of the rotational collapse of a landslide coupled with the shearband governing equations (15) and (20). The coupling variables are the slide velocity $v_{d}(t)$, the average pore pressure at the shearband-block interface $u_{d}(t)$ and the friction angle $\varphi_{c s}^{\prime}(t)=\varphi_{c s}^{\prime}(\gamma, \dot{\gamma}, \theta)$.

\subsection{Numerical implementation}

The coupled equations (20), (24) and (29) for the rotational sliding case, and (20), (24) and (25) for the planar sliding case were discretized using a finite difference scheme and integrated numerically with the necessary initial and boundary conditions (equations (30), (31) and (32) discussed below) to determine the evolution of temperature, excess pore pressure and slide velocity with time. The heat and pore pressure equations are nonlinear partial differential equations (PDEs), and were discretized using a Forward-Time Centered-Space explicit finite difference scheme. Stability of the numerical scheme was ensured by controlling the size of the time-step, on the basis of a von Neumann type stability analysis and numerical experimentation. Equation (29), or equation (25), which are ordinary differential equations, were discretized with a standard fourth-order Runge-Kutta scheme using the same timestep as for the PDEs [32].

The finite difference equations were integrated in a spatial domain representing the shearband and the surrounding soil. The shearband is assumed to be embedded in a clay layer of the same characteristics, whose thickness is much larger than the shearband thickness $d$. Shear straining and consequent heat production occur within 
the shearband only. The extent of the spatial domain considered was 10 times the thickness of the shearband and it was assumed to be uniform in hydraulic, thermal and geotechnical properties (Figure 5). In line with [12], the assumption was made that at a large distance from the band (i.e. at the domain boundaries) the excess pore pressure is zero and the temperature is equal to its ambient value:

$$
u( \pm \infty, t)=0 ; \quad \theta( \pm \infty, t)=\theta_{\text {ref }}
$$

The velocity profile through the thickness of the domain is defined as:

$$
\begin{cases}v=0 & \mathrm{z} \in[-\infty, 0] \\ v=v_{d}(\mathrm{t}) \frac{\mathrm{z}}{\mathrm{d}} & \mathrm{z} \in[0, d] \\ v=v_{d}(\mathrm{t}) & \mathrm{z} \in[d,+\infty]\end{cases}
$$

The initial conditions are:

$$
\theta(z, 0)=\theta_{\text {ref }} ; \quad u(z, 0)=0 ; \quad v(z, 0)=0
$$

Following [12], to numerically initiate movement of the slide a small, $0.1 \%$ reduction of the friction angle was imposed. The equations were integrated numerically for a time window of 10 seconds after slide initiation. Numerical results for rotational and planar sliding are presented in Sections 4 and 5 respectively.

\section{Numerical example: analysis of the Vajont landslide}

As an example, the model is applied to available field data of the Vajont catastrophic landslide, which appears to best suit this purpose due to the large amount of information available on the geological and geomechanical aspects of the slide.

The stratigraphy of the site consists of a succession of limestone and marl, intercalated by clay-rich layers (35-80\% of clay minerals) of $0.5-17.5 \mathrm{~cm}$ thickness [38]. Following a prolonged (longer than 2 years) period of creep, a volume of approximately $270 \mathrm{Mm}^{3}$ of almost intact rock collapsed into the underlying reservoir with a final velocity of the order of $25-30 \mathrm{~m} / \mathrm{s}$ [38]. As reported by Muller [39], the 
sliding velocity measured a few hours before final collapse was around $20 \mathrm{~cm} /$ day. The slide is reported to have reached its final velocity in less than a minute, revealing a dramatic dynamic reduction of the shearing resistance. Vardoulakis [12] calculated that the time needed for this dynamic reduction to take place, with a simultaneous increase of the slide's velocity to the observed values, was around $10 \mathrm{sec}$.

The kinematics of this slide may be approximated, at least for the early parts of the catastrophic sliding stage, by a rotational movement as emerges by examining, for example, 'Section 5' of Vajont [38]. The same friction circle analysis as in [12] is adopted.

\subsection{Parameter determination}

Geometrical and material parameters for 'Section 5' of Vajont are used consistently with [12] where possible; these are summarized in Table 1. The additional parameters introduced by the constitutive model of Section 2 are separately discussed below.

In order to calculate the thermo-plastic contraction coefficient (Section 2.2), the soil's void ratio $e$ at critical state is needed. Due to lack of direct measurements for the particular clay relevant to Vajont, we use a crude estimate based on an average, typical value of the critical state parameter $\Gamma$ (Table 1 ). This parameter represents the intercept at $1 \mathrm{kPa}$ of the critical state line in $(1+e)$ vs. $\ln \left(p^{\prime}\right)$ space, expressed as (e.g., [19])

$$
(1+e)=\Gamma-\lambda \ln p^{\prime}
$$

from which we may calculate $e$ by setting $p^{\prime}=p_{0}^{\prime}$.

The plastic compressibility modulus $\tilde{\beta}$ can be calculated from the hardening law in isothermal conditions. Setting $\theta=\theta_{\text {ref }}$ and taking the time derivative of equation (1), we obtain

$$
\dot{\varepsilon}_{v}^{p}=\frac{1}{\tilde{\beta}} \frac{\dot{\sigma}_{c}}{\sigma_{c}}
$$

which by comparison with the standard Modified Cam Clay hardening relationship (e.g., see [19]) yields 


$$
\tilde{\beta}=\frac{1+e}{\lambda-\kappa}
$$

The thermal expansion coefficient $\beta_{s}$ is, according to Laloui et al. [9], temperature- and mean stress-dependent, introducing a double source of nonlinearity in elasticity. Here we ignore this dependence due to lack of direct experimental data and the mathematical simplifications brought about by adopting a linear thermoelastic law. Thus we calculate the coefficient $\beta_{s}$ as

$$
\beta_{s}=(1-n) \alpha_{s}+n \alpha_{w}
$$

where $n=e /(1+e)$ is the porosity of the soil, $\alpha_{s}=3 * 10^{-5}{ }^{\circ} \mathrm{C}^{-1}$ is the coefficient of thermal expansion of the clay particles and $\alpha_{w}=2.75 * 10^{-4}{ }^{\circ} \mathrm{C}^{-1}$ that of water [12]. As a result, $\beta_{s}=7.41 * 10^{-5}{ }^{\circ} \mathrm{C}^{-1}$. This represents an average value for clays, in line with experimental findings (e.g. see $[16,17,32])$.

The rate of thermal friction softening $\tilde{g}$ may be calibrated using the (few) experimental data available, with the awareness that this data is not necessarily representative of the Vajont clay. From the data presented by Laloui et al. [9] we can extract an average slope of decrease of the friction angle with temperature: a decrease of $\Delta \varphi \approx 10^{\circ}$, corresponding to a decrease of the critical state parameter by $\Delta M \approx 0.36$ occurs over a temperature increase of $\Delta \theta \approx 60^{\circ} \mathrm{C}$. We deduce $10^{-3} \leq \tilde{g} \leq 10^{-2}$.

The material parameter $\gamma$ that controls thermal softening, i.e. the sensitivity of the apparent preconsolidation stress with temperature, is introduced by the hardening law of equation (1) and can be chosen within a relatively wide range. Some experimentally measured values of $\gamma$ have been presented for different clays in [7], from which we may deduce a range of $5 \times 10^{-3} \leq \gamma \leq 5 \times 10^{-1}$. This parameter also appears in equation (10) giving the thermoplastic contraction coefficient: while $\gamma$ is not routinely measured, the other parameters featuring in equation (10) represent standard, well-established geotechnical properties. It is therefore reasonable to first assign a sensible value to all other parameters and define $\gamma$ last, based on overall 
consistency arguments, also due to the lack of available information regarding the exact thermal softening properties of the Vajont clay.

An appropriate value for $\gamma$ must be selected, for given values of all other parameters, so that the thermoplastic contraction coefficient $\alpha_{c}^{t p}$ is negative for all values of temperature, and consequently the pressurization coefficient $\lambda_{m}$ in equation (11) is positive and assumes values that are in line with earlier findings. Numerical experimentation showed that, for the temperature range $10 \leq \theta \leq 150{ }^{\circ} \mathrm{C}$, the value of $\lambda_{m}$ becomes higher and more realistic if $\gamma$ is chosen towards the lower end of the range established above. Figure 6 shows that for decreasing values of $\gamma$, the variation of the pressurization coefficient with temperature is smaller and tends to an average value of $\bar{\lambda}_{m} \approx 0.012 \mathrm{MPa}$ which agrees with the range of measured values for clay reported in the literature (Section 2.2), and is also not far from that proposed in [12]. It appears therefore reasonable to use a lower-mid-range value of $\gamma=10^{-2}$.

\subsection{Numerical results}

\subsubsection{Case of thermal friction softening}

We start the analysis from the simpler case where only thermal friction softening (TFS) occurs, since the concern was raised that this feature may lead to mathematical ill-posedness for the heat equation. By neglecting strain- and strain-rate softening as a first step, we will be able to investigate more efficiently the potential impact of TFS, which constitutes the least established feature of the proposed model.

With these settings, temperature and pore pressure were computed at each gridpoint of the spatial domain and isochrones through the domain were produced at key time values (Figures 7 and 8). It can be seen that the maximum temperature reached inside the shearband is about $145{ }^{\circ} \mathrm{C}$ after 10 seconds (about 8 seconds after the outbreak of acceleration, as can be seen from the velocity profile in Figure 9). This is well below the water vaporization threshold at the given pressure (cf. Section 4.3). The overburden corresponds to an initial vertical effective stress of $2.38 \mathrm{MPa}$ which, as a consequence of the effective stress principle, is also the maximum value that excess pore pressure can reach. It can be seen that this value is approached as the excess pore pressure exceeds $2 \mathrm{MPa}$ after $10 \mathrm{~s}$ from slide triggering.

In Figures 9 and 10 the calculated slide velocity and displacement are plotted with dashed lines. From the velocity plot we can distinguish two phases: the 
'triggering phase', from $t=0 \mathrm{~s}$ to $t \approx 2 \mathrm{~s}$ in which the velocity profile shows a negligible increase, and the slide's catastrophic 'activation phase' after $t \approx 2 \mathrm{~s}$, when the acceleration of the mass abruptly increases, corresponding to a substantial rise in the pressurization rate as evident from Figure 8.

\subsubsection{Case of thermal-, displacement- and velocity- friction softening}

We will now analyze the more general case, where the critical state parameter decreases with displacement, velocity and temperature. The values of the static and dynamic friction-softening rates $a_{1}$ and $a_{2}$ (Section 3.1.1) were chosen to be the same as in [12], based on the experimental evidence on the Vajont clay reported in [31]. In Figures 11 and 12 the temperature and pore pressure isochrones are plotted for this case of 'full' friction softening (FFS), in Figures 9 and 10 the velocity and displacement profiles are plotted with solid lines for a time window of 10 seconds after triggering. In comparison with the TFS case (dashed lines), we can observe that:

Sliding is activated earlier, after about half a second from triggering as opposed to about 2 seconds in TFS case, as a result of the quicker decrease of the friction angle with increasing temperature, displacement and velocity. Due to this earlier 'activation' a higher final velocity of $v_{(\mathrm{t}=10 \mathrm{~s})}=26.3 \mathrm{~m} / \mathrm{s}$ is reached, as opposed to $21 \mathrm{~m} / \mathrm{s}$ in TFS case. The displacement after 10 seconds is also substantially larger (119.5 m).

A higher maximum temperature $\left(\theta_{\max }=147.7^{\circ} \mathrm{C}\right)$ is reached within the shearband at $t=10$ seconds, due to the larger accumulated shear strain and consequently higher dissipation of energy into heat. Nevertheless, this value is not substantially larger than that of the TFS case $\left(\theta_{\max }=145.5^{\circ} \mathrm{C}\right)$ since at the same time the friction angle decreases more rapidly, capping dissipation.

In both cases, however, a velocity of about $20 \mathrm{~m} / \mathrm{s}$ and a displacement of about $80 \mathrm{~m}$ are reached approximately 8 seconds after activation of catastrophic sliding.

\subsubsection{Case of displacement- and velocity- friction softening}

To assess the relative importance of the two main components of the FFS law (thermal-dependence and strain-, strain rate- dependence) in the predicted values of sliding velocity, it is worth considering the case where no thermal friction softening (NTS) takes place. This is achieved by setting $\tilde{g}=0$ in the friction-softening law of equation (19). 
The results for this scenario show no appreciable difference from the case of FFS. The calculated values for slide velocity and displacement after 10 seconds from triggering are smaller than those obtained for full softening by some $0.5-1 \%$, which in the context of this model is negligible. The comparison of results obtained for the three examined friction-softening scenarios highlights the substantially more important role played by strain- and strain rate-friction softening in determining slide activation, and is due to the specific form of the softening law: the decrease of $M$ towards the residual value according to the (twofold) hyperbolic law $\hat{M}(\gamma, \dot{\gamma})$ of equation (19) is so fast that no perceptible difference is brought about by superimposing a linear decrease with temperature.

\subsection{Discussion of the numerical results}

All simulations reported in Sections 4.2.1, 4.2.2 and 4.2.3 predict a similar behavior and magnitude of results to those observed in Vajont, and are in accordance with those calculated by the model of Vardoulakis [12]. In particular, a predicted final velocity of $20-25 \mathrm{~m} / \mathrm{s}$ is in the bulk of the reported observations for the Vajont slide [38].

The TFS simulation shows that thermal-friction softening alone can account for catastrophic sliding, being potentially an important mechanism. The choice of a thermal sensitivity value of $\tilde{g}=10^{-2}$ proved to be reasonable, as it leads to realistic predictions and matches with available experimental data on thermal-friction softening. On the other hand, the simulations for the case of TFS should be seen only as a means of investigating the impact of the newly introduced mechanism, since a realistic simulation must account for the better established strain and strain-rate softening mechanisms as well. Such mechanisms were included in the FFS and NTS simulations, leading to very similar predictions.

The numerical results presented give realistic predictions for the final collapse phase of the Vajont case history. We remark, however, that the intermittent, creep-like sliding phases of Vajont that preceded the catastrophic run-out phase cannot be reproduced by this model. Finally, it is worth observing that the landslide model ceases to be valid as soon as the temperature within the shearband reaches the vaporization limit of the pore water for the current pressure. After this transition point, the governing equations would need substantial modifications since the energy balance should account for the evaporation heat, and fluid flow would take place 
under conditions of partial saturation. Within the so-called "undrained-adiabatic limit", Vardoulakis [11] showed that the presence of vapor would decrease the fluid compressibility and result in the reduction of excess pore pressure and apparent frictional softening. Such effects would arguably only have a minor influence on the acquired speed of the landslide. Nevertheless, since the model's assumptions will break down as soon as the vaporization threshold is attained, the simulations should be considered well-founded only as long as the maximum temperature $\theta_{\max }$ reached in the slip plane remains below the vaporization threshold temperature $\theta_{v a p}$. This threshold may be calculated from the phase change line of water [12], as a function of the current pore water pressure $p_{c r}$. In the Vajont case, by setting the maximum pore pressure that can be reached equal to the initial overburden pressure $p_{c r} \approx \sigma_{n}^{\prime}=2.38$ $\mathrm{MPa}$, we get as vaporization threshold temperature $\theta_{\text {vap }} \approx 210^{\circ} \mathrm{C}$. We remark that in our calculations the condition $\theta_{\max }<\theta_{v a p}$ was always found to hold.

More detailed confirmation of the correctness of the various aspects of the model could come from laboratory tests. In particular, high-speed dynamic shear tests would give further insight into the shearband formation mechanism and the softening properties of the Vajont clay. More accurate data on the thermal properties of the soil would also be desirable, especially on the possible dependence of its friction angle on temperature, an issue on which no data is currently available. In addition, the proportion of the externally applied energy that is converted into heat during rapid shearing should ideally be quantified for the Vajont clay, although no standard methods or techniques currently exist for such measurements. Finally, the permeability of the shearband soil at residual state should be determined, preferably using samples that have previously undergone prolonged shearing: insitu measurements may lead to an overestimation of permeability at the shearband due to the presence of macroscopic features such as fractures.

\subsection{Impact of friction-softening mechanisms}

To investigate the impact of friction-softening mechanisms in the dynamic evolution of a landslide, a calculation was performed for Vajont neglecting any friction softening mechanism, i.e. any reduction of the critical state parameter. In Figure 13 the velocity profile is plotted for this case. The drastic difference in the calculated values shows how sensitive the timescale of the phenomenon is to the 
friction softening mechanisms. After 10 seconds the velocity is still of the order of $\mathrm{mm} / \mathrm{sec}$, as thermal pressurization has not yet started to develop appreciably. A longer time is needed for catastrophic acceleration to occur in this case, due to the fact that at early stages of sliding, the high friction brings about limited displacement. This in turn provides a slow heat production, that has the time to partially diffuse away from the shear zone. Nevertheless, Figure 13 also shows that prolonged shearing does provide the gradual build-up of thermal pressurization. It can be seen that even thermal pressurization on its own is a major destabilizing mechanism as it eventually leads to drastic landslide acceleration in a comparably catastrophic manner: a velocity of about $25 \mathrm{~m} / \mathrm{s}$ is reached 1 minute after triggering.

\section{Impact of the pressurization mechanism}

The potential impact of the thermal pressurization mechanism in the dynamic evolution of a landslide is further demonstrated by a set of numerical predictions presented below. To isolate the effect of the particular mechanism, it was assumed that no friction softening takes place. Also, to simplify the geometry and produce more readily comparable results, an infinite slope geometry was assumed whose dynamics is described by equation (25). Typical parameter values were used, listed in Table 2. The predicted velocity for the first $10 \mathrm{~s}$ after slide initiation is plotted in Figure 14, for different values of the thickness $H$ of the overburden ranging from 50 to 400 meters.

If thermal pressurization is neglected, the velocity reached after $10 \mathrm{~s}$ is of the order of meters/hour, it is independent of $H$ and it is given by the thin dashed line at the bottom of Figure 14. If, on the other hand, thermal pressurization is allowed to develop, Figure 14 shows that the slide velocity after 10 s increases with $H$ by several orders of magnitude, up to $10 \mathrm{~m} / \mathrm{s}$ in the case of $H=400 \mathrm{~m}$. The reason for such sensitivity of slide acceleration to the overburden thickness lies in the dissipation term D of equation (15): the larger $H$ is, the higher the effective stress and therefore the heat production, bringing about a higher pressurization rate that causes a quicker reduction of shear resistance. These results show that, counter to engineering intuition but in line with geological field observations [39], thermal pressurization will cause thicker sliding masses to accelerate faster and thus have a disproportionately higher catastrophic impact.

\section{Conclusions}


In this work, a new model for the final collapse stage of catastrophic landslides has been proposed, taking into account a pressurization phase due to frictional heating. It is based on the model presented in [12], which was here significantly modified to use a more general and more realistic constitutive law for the soil; this constitutive law incorporates the experimentally established mechanisms of thermaland thermal friction-softening [9]. As a result of this development it was shown that the pressurisation coefficient, quantifying pore pressure build-up due to temperature increase, is not an independent model parameter as previously assumed in [12] but can be determined in terms of other thermo-mechanical material parameters and the value of state variables.

The governing equations of the model were integrated numerically and used to analyze the Vajont landslide, demonstrating that realistic predictions for the final velocity of the slide can be obtained. Parametric analysis showed that the thermal friction softening mechanism is of secondary importance for the development of catastrophic acceleration, compared to the better established mechanisms of static and dynamic material friction softening. It was also found that, although the mechanism of thermal pressurization alone can cause a comparably catastrophic dynamic evolution of a slide even in the absence of any softening, the latter is the mechanism most affecting the timescale of final collapse. However, all other parameters being equal, thermal pressurization will cause thicker slides to accelerate faster, increasing their catastrophic potential. This is in contrast to classical stability analysis of uniform slopes, where the thickness of the overburden does not enter.

Despite the simplifications inherent in it, the thermo-mechanical landslide model presented here is able to interpret the key aspects of thermal pressurization and to provide a useful estimate of the order of magnitude of velocity and displacement that a coherent slide can reach. Thus it constitutes a useful step towards the development of a general modeling tool, able to capture the dynamic emergence of thermomechanical failure in large-scale landslides of various geometries and in situ conditions.

\section{Appendix A: Thermo-elasto-plastic constitutive model derivation}


Within the range of small deformations we can assume the validity of additive decomposition of total strain into elastic and plastic parts, as well as the corresponding decomposition of their rates:

$$
\dot{\boldsymbol{\varepsilon}}=\dot{\boldsymbol{\varepsilon}}^{e}+\dot{\boldsymbol{\varepsilon}}^{p}
$$

In the presence of thermal loading, elastic strains can be separated into two contributions: a mechanical-elastic and a thermo-elastic part, so that from equation (A1),

$$
\dot{\boldsymbol{\varepsilon}}=\dot{\boldsymbol{\varepsilon}}^{m e}+\dot{\boldsymbol{\varepsilon}}^{t e}+\dot{\boldsymbol{\varepsilon}}^{p}
$$

The thermoelastic relationships imply recoverable volumetric dilation with increased temperature, and can be obtained from standard continuum mechanics (e.g., [41]). The strain rate components of an isotropic body subjected to thermal loading are expressed as

$$
\dot{\boldsymbol{\varepsilon}}^{t e}=\alpha \boldsymbol{\delta}_{i j} \dot{\theta}
$$

where $\alpha$ is the thermal elastic expansion coefficient and $\boldsymbol{\delta}_{i j}$ is the Kronecker delta.

On the other hand, Laloui and Cekerevac [7] provided for the isotropic thermoelastic strain the expression $\dot{\varepsilon}_{v}^{t e}=\beta_{s} \dot{\theta}$, which in vector form becomes

$$
\dot{\boldsymbol{\varepsilon}}^{t e}=\mathbf{C}^{T e} \dot{\theta}
$$

where $\mathbf{C}^{T e}=\left(\beta_{s} \boldsymbol{\delta}_{i j}\right) / 3$. From the above we deduce, by comparison with equation (A3), that $\alpha=\beta_{s} / 3$.

Adding up the mechanical-elastic part (standard Hooke's law) yields the socalled Duhamel-Neumann relations, which in turn can be inverted to give the thermoelastic constitutive equations: 


$$
\dot{\boldsymbol{\sigma}}=\left(K-\frac{2}{3} G\right) \boldsymbol{\delta}_{i j} \dot{\boldsymbol{\varepsilon}}^{m e}+2 G \dot{\boldsymbol{\varepsilon}}^{m e}-\beta_{s} K \boldsymbol{\delta}_{i j} \dot{\theta}
$$

[41], where $K$ and $G$ are the instantaneous bulk and shear modulus respectively:

$$
K=\frac{\partial p^{\prime}}{\partial \varepsilon_{v}^{e}}=\frac{\mathrm{v} p^{\prime}}{\kappa} ; \quad G=\frac{3(1-2 v)}{2(1+v)} K
$$

In the above, $\kappa$ is the slope of the elastic recompression line, $\mathrm{v}$ the specific volume and $v$ the soil's Poisson ratio. Equation (A5) can be rewritten as

$$
\dot{\boldsymbol{\sigma}}=\mathbf{D}^{m e} \dot{\boldsymbol{\varepsilon}}^{m e}+\mathbf{D}^{t e} \dot{\theta}
$$

where $\mathbf{D}^{m e}$ is the tensor of elastic moduli (e.g., [42]), and the thermal tensor is

$$
\mathbf{D}^{t e}=-\beta_{s} K \boldsymbol{\delta}_{i j} .
$$

We use an associated flow rule to define the relative magnitudes of various components of plastic deformation:

$$
\dot{\boldsymbol{\varepsilon}}^{p}=\dot{\lambda} f_{\sigma}
$$

where $f$ is the temperature-dependent Modified Cam Clay yield function of equation (3), $\dot{\lambda}$ the plastic multiplier and the subscript denotes the partial derivative with respect to stress.

Substituting equation (A2), (A4) and (A9) into equation (A7) yields

$$
\dot{\boldsymbol{\sigma}}=\mathbf{D}^{m e} \dot{\boldsymbol{\varepsilon}}-\left(\mathbf{D}^{m e} \mathbf{C}^{t e}-\mathbf{D}^{t e}\right) \dot{\theta}-\mathbf{D}^{m e} \dot{\lambda} f_{\boldsymbol{\sigma}}
$$

The consistency condition $\dot{f}=0$, expressing the need for the stress to remain on the yield surface during yielding, is written as 


$$
\dot{f}=f_{\mathbf{\sigma}} \dot{\boldsymbol{\sigma}}+f_{\varepsilon_{v}^{p}} \dot{\varepsilon}_{v}^{p}+f_{\theta} \dot{\theta}=0
$$

Substituting equation (A10) into equation (A11) and solving for the plastic multiplier yields

$$
\dot{\lambda}=\frac{f_{\sigma} \mathbf{D}^{m e} \dot{\boldsymbol{\varepsilon}}+\left(f_{\theta}-f_{\boldsymbol{\sigma}} \mathbf{D}^{m e} \mathbf{C}^{t e}+f_{\boldsymbol{\sigma}} \mathbf{D}^{t e}\right) \dot{\theta}}{H}
$$

where $H=\left(f_{\sigma} \mathbf{D}^{m e} f_{\sigma}-f_{\varepsilon_{v}^{p}} f_{p^{\prime}}\right)$, leading after algebraic manipulation to equation (6). Substituting equation (6) into equation (A10) and regrouping terms, we obtain

$$
\dot{\boldsymbol{\sigma}}=\dot{\boldsymbol{\sigma}}^{e}-\dot{\lambda} \mathbf{D}^{m e} g_{\boldsymbol{\sigma}}+\left(\mathbf{D}^{t e}-\mathbf{C}^{t e} \mathbf{D}^{m e}\right) \dot{\theta}=\mathbf{D}^{m e p} \dot{\boldsymbol{\varepsilon}}+\mathbf{D}^{t e p} \dot{\theta}
$$

which represents the stress-strain rate equation in the general case of thermoelasto-plastic loading.

To complete the description of the thermo-plasticity framework, we need to specify the hardening rule, linking plastic deformation to the change in size of the yield locus through the apparent preconsolidation stress. The thermo-plastic hardening rule is obtained by taking the rate of equation (1)

$$
\dot{\sigma}_{c}^{\prime}\left(\dot{\varepsilon}_{v}^{p}, \dot{\theta}\right)=\sigma_{c 0}^{\prime} \exp \left(\tilde{\beta} \varepsilon_{v}^{p}\right)\left\{\beta\left[1-\gamma \log \left(\frac{\theta}{\theta_{0}}\right)\right] \dot{\varepsilon}_{v}^{p}-\gamma \frac{\dot{\theta}}{\theta}\right\}
$$

which, by substituting the flow rule of equation (A9), may be rewritten as

$$
\dot{\sigma}_{c}^{\prime}\left(\dot{\varepsilon}_{v}^{p}, \dot{\theta}\right)=A \dot{\theta}+B \dot{\lambda}
$$

where:

$$
\begin{aligned}
& A=-\left[\sigma_{c 0}^{\prime} \exp \left(\tilde{\beta} \varepsilon_{v}^{p}\right)\right] / \theta \\
& B=\tilde{\beta}\left[\sigma_{c 0}^{\prime} \exp \left(\tilde{\beta} \varepsilon_{v}^{p}\right)\right]\left[1-\gamma \log \left(\theta / \theta_{0}\right)\right] f_{p} .
\end{aligned}
$$




\section{Appendix B: Thermo-plastic contraction coefficient}

In order to derive the expression of the thermo-plastic contraction coefficient it is convenient to rewrite the plastic multiplier of equation (A12) in terms of the stress invariants p' and q:

$$
\dot{\lambda}=\frac{K f_{p} \dot{\varepsilon}_{v}+3 G f_{q} \dot{\varepsilon}_{q}+\left(f_{\theta}-2 K \beta_{s} f_{p}\right) \dot{\theta}}{\tilde{H}}
$$

where $\tilde{H}=K f_{p}^{2}+3 G f_{q}^{2}-f_{\varepsilon_{v}^{p}} f_{p}$. Assuming isotropic loading conditions,

$$
p^{\prime}=\sigma_{c}^{\prime} ; \quad q=0 ; \quad \dot{\varepsilon}_{q}=0
$$

The flow rule of equation (A9) is reformulated, employing equation (B1), as

$$
\dot{\boldsymbol{\varepsilon}}_{v}^{p}=F_{\theta} \dot{\theta}+F_{m} \dot{\varepsilon}_{v}^{m}
$$

where

$$
F_{\theta}=\frac{f_{\theta}-2 K \beta_{s} f_{p}}{\tilde{H}} M^{2} \sigma_{c}^{\prime}
$$

is the factor representing the thermal contribution to volumetric plastic strain rates, and

$$
F_{m}=\frac{K f_{p}}{\tilde{H}} M^{2} \sigma_{c}^{\prime}
$$

represents the isotropic mechanical contribution. The thermoplastic contraction coefficient $\alpha_{c}^{p}$ is thus equal to factor $F_{\theta}$. By calculating the derivatives of the yield surface at conditions (B2), we obtain from equation (B4) 


$$
\alpha_{c}^{p}=F_{\theta}=\frac{\gamma \sigma_{c}^{\prime}-2 K \theta\left[1-\gamma \log \left(\theta / \theta_{r e f}\right)\right] \beta_{s}}{\theta\left[1-\gamma \log \left(\theta / \theta_{r e f}\right)\right]\left(K+\tilde{\beta} \sigma_{c}^{\prime}\right)} .
$$

Substituting into equation (B6) the bulk modulus from equation (A6) and the definition of plastic compressibility from equation (35), we obtain the final form of the thermoplastic contraction coefficient given in equation (10).

\section{Appendix C: Stress state assumptions in the slip plane}

Considering oedometric conditions and assuming that the two in-plane stresses are equal ( $\sigma_{x x}^{\prime}=\sigma_{y y}^{\prime}$, with reference to the geometry of Figure 2), from Hooke's law we obtain

$$
\sigma_{x x}^{\prime}=\sigma_{y y}^{\prime}=\left(\frac{v}{1-v}\right) \sigma_{z z}^{\prime}
$$

Hence, by substituting into equation (C1) the definition of mean effective stress

$$
p^{\prime}=\frac{1}{3}\left(\sigma_{x x}^{\prime}+\sigma_{y y}^{\prime}+\sigma_{z z}^{\prime}\right)
$$

we obtain

$$
\sigma_{z z}^{\prime}=\sigma_{n}^{\prime}=3\left(\frac{1-v}{1+v}\right) p^{\prime}
$$

The oedometric compressibility coefficient may be expressed as [12]

$$
c=n c_{w}+c_{s k}
$$

where $n=e /(1+e)$ is the porosity of the soil, $c_{w}$ the compressibility of water and $c_{s k}$ the compressibility of the soil skeleton, obtained in one-dimensional conditions. The latter can be expressed as 


$$
c_{s k}=\left(c_{s w} \frac{\partial p^{\prime}}{\partial \sigma_{z z}^{\prime}}\right)_{\theta=\text { const. }}
$$

where

$$
c_{s w}=\left(\frac{\partial \varepsilon_{v}}{\partial p^{\prime}}\right)_{\theta=\text { const. }}
$$

is the isotropic elastic 'swelling' soil compressibility, corresponding to the compression modulus in isotropic elastic unloading. This choice is justified by the fact that under conditions of effective stress reduction due to pore pressure increase (cf. Section 2.2), the soil skeleton practically undergoes elastic unloading $[12,25]$. The dependency on temperature of $c_{s w}$ is weak and thus can be neglected [14]. By solving equation (C3) for $p^{\prime}$ and substituting into equation (C5) we get

$$
c_{s k}=\frac{1}{3}\left(\frac{1+v}{1-v}\right) c_{s w} .
$$

In the above, $c_{s w}$ may be calculated by substituting into equation (C6) the volumetric strain in terms of void ratio (e.g., [19]), yielding

$$
c_{s w}=\frac{\kappa}{(1+e) p^{\prime}}
$$

where $\kappa$ is the slope of the unloading-reloading line, $e$ the void ratio and $p^{\prime}=p_{0}^{\prime}$ the static value of mean effective stress in the shearband.

\section{Appendix D: Dissipation function}

In order to employ the constitutive law of Section 2.1, dissipation can be reformulated in the principal stress space as: 


$$
D=\sigma_{1} \dot{\varepsilon}_{1}^{p}+\sigma_{2} \dot{\varepsilon}_{2}^{p}+\sigma_{3} \dot{\varepsilon}_{3}^{p}
$$

which, by substituting the plastic strain rate components in terms of the flow rule of equation (A9), becomes

$$
D=\dot{\lambda}\left[\sigma_{1} \frac{\partial f}{\partial \sigma_{1}}+\sigma_{2} \frac{\partial f}{\partial \sigma_{2}}+\sigma_{3} \frac{\partial f}{\partial \sigma_{3}}\right]
$$

where $\sigma_{1}, \sigma_{2}$ and $\sigma_{3}$ are the principal stresses, $f$ is the yield function of equation (3) (used also as a plastic potential) and $\dot{\lambda}$ is the plastic multiplier.

The yield function $\mathrm{f}$ can be written in general in terms of the three stress invariants, i.e. the mean effective stress p', the stress deviator q and the Lode angle $\theta_{L}$ (see [43]). The stress deviator is:

$$
q=\sqrt{\frac{1}{2}\left[\left(\sigma_{2}^{\prime}-\sigma_{3}^{\prime}\right)^{2}+\left(\sigma_{3}^{\prime}-\sigma_{1}^{\prime}\right)^{2}+\left(\sigma_{1}^{\prime}-\sigma_{2}^{\prime}\right)^{2}\right]}
$$

In plane strain conditions (Section 3.1), $\theta_{L}=0$ and the yield function is expressed by (3) provided that the critical state parameter $M$ is defined as:

$$
M=\sin \varphi_{c s}^{\prime} \sqrt{3}
$$

where $\varphi_{c s}^{\prime}$ is the friction angle of the soil at critical state.

By calculating the derivatives of the yield function [32] and substituting the definition of mean effective stress (C2), we obtain from equation (D2):

$$
\begin{aligned}
D & =\dot{\lambda}\left[3 \sigma_{1}\left(\sigma_{1}-p^{\prime}\right)+3 \sigma_{2}\left(\sigma_{2}-p^{\prime}\right)+3 \sigma_{3}\left(\sigma_{3}-p^{\prime}\right)\right]= \\
& =\dot{\lambda}\left[2\left(\sigma_{1}^{2}+\sigma_{2}^{2}+\sigma_{3}^{2}-\sigma_{1} \sigma_{2}-\sigma_{1} \sigma_{3}-\sigma_{2} \sigma_{3}\right)\right]= \\
& =\dot{\lambda}\left[\left(\sigma_{1}-\sigma_{2}\right)^{2}+\left(\sigma_{3}-\sigma_{1}\right)^{2}+\left(\sigma_{2}-\sigma_{3}\right)^{2}\right] .
\end{aligned}
$$

which becomes, in view of equation (D3), 


$$
D=2 \dot{\lambda} q^{2}
$$

By substituting in the above the critical state condition of equation (13), we finally obtain equation (16).

\section{Appendix E: New form of heat equation}

The final step towards the incorporation of the thermo-plastic constitutive model into the landslide model is expressing the strain rate $\dot{\varepsilon}_{q}$ in equation (B1) in terms of the variables of the 1-D shearband problem. A general form for the deviatoric strain rate is (e.g., see [19])

$$
\dot{\varepsilon}_{q}=\frac{1}{3} \sqrt{2\left[\left(\dot{\varepsilon}_{y y}-\dot{\varepsilon}_{z z}\right)^{2}+\left(\dot{\varepsilon}_{z z}-\dot{\varepsilon}_{x x}\right)^{2}+\left(\dot{\varepsilon}_{x x}-\dot{\varepsilon}_{y y}\right)^{2}\right]+3\left(\dot{\gamma}_{x y}^{2}+\dot{\gamma}_{y z}^{2}+\dot{\gamma}_{x z}^{2}\right)}
$$

In this case, due to plane strain conditions $\dot{\varepsilon}_{y y}=0$ and $\dot{\gamma}_{z y}=\dot{\gamma}_{x y}=0$ (c.f. Figure 2). Moreover, the 1-D hypothesis implies that $\dot{\varepsilon}_{x x}=0$. Due to the assumed critical state condition, $\dot{\varepsilon}_{v}=\dot{\varepsilon}_{x x}+\dot{\varepsilon}_{y y}+\dot{\varepsilon}_{z z}=0$ so that also $\dot{\varepsilon}_{z z}=0$. Equation (E1) is therefore reduced to

$$
\dot{\varepsilon}_{q}=\frac{\sqrt{3}}{3} \dot{\gamma}_{z x}
$$

where $\dot{\gamma}_{z x}=\partial v_{x} / \partial z$, and $v_{x}=v(z, t)$ is the velocity within the shearband in the direction of motion, expressed by equation (14), so that the above becomes

$$
\dot{\varepsilon}_{q}=\frac{\sqrt{3}}{3} \frac{\partial v_{x}}{\partial z}=\frac{\sqrt{3}}{3} \frac{v_{d}(t)}{d}
$$

and the plastic multiplier of equation (B1) can be finally written in the form

$$
\dot{\lambda}=F_{1} \frac{\partial \theta}{\partial t}+F_{2} \frac{v_{d}(t)}{d}
$$


where

$$
\begin{aligned}
& F_{1}=\frac{f_{\theta}-2 K \beta_{s} f_{p}}{\tilde{H}} \\
& F_{2}=\frac{\sqrt{3} G f_{q} \dot{\varepsilon}_{q}}{\tilde{H}}
\end{aligned}
$$

The heat equation (15) can then be finally written, by adopting equation (16) for the dissipation and equation (E4) for the plastic multiplier, as $[32,43]$

$$
\frac{\partial \theta}{\partial t}=D_{i} \frac{\partial^{2} \theta}{\partial z^{2}}+F_{i} \frac{v_{d}(t)}{d}
$$

where

$$
\begin{gathered}
D_{i}=\frac{k_{m}}{1-\frac{\left(M \sigma_{c}^{\prime}\right)^{2}}{2 C_{f}} F_{1}}, \\
F_{i}=\frac{\left(M \sigma_{c}^{\prime}\right)^{2} F_{2}}{2 C_{f}-\left(M \sigma_{c}^{\prime}\right)^{2} F_{1}} .
\end{gathered}
$$

Coefficients $D_{i}$ and $F_{i}$ depend on pore pressure $u$, temperature $\theta$ and, if material friction softening takes place, also on the shear strain $\gamma$ and strain rate $\dot{\gamma}$.

The final form of the heat diffusion-generation equation within the framework of thermal critical state soil mechanics is given by equation (E6). Compared to the original equation (15), it can be noticed that the diffusion term is now non-linear due to the temperature-dependent factor $\left[1-F_{1}\left(M \sigma_{c}^{\prime}\right)^{2} / 2 C_{f}\right]$. Hence, defining the term $D_{i}$ as a new thermal diffusivity allows us to formally define equation (E6) a nonlinear diffusion-generation equation.

\section{Appendix F: Friction softening law}


The friction softening law defined by [12] for the Vajont clay based on the ring shear experimental data of [31] defines the evolution of the friction coefficient $\hat{\mu}$, related to the soil mobilised friction angle as $\hat{\mu}=\tan \phi^{\prime}$, as a hyperbolic function:

$$
\hat{\mu}=\mu_{r}+\left(\mu_{p}-\mu_{r}\right) \frac{1}{1+a_{1} \frac{x_{d}}{d}}
$$

where

$$
\mu_{r}=\mu_{r d}+\left(\mu_{r s}-\mu_{r d}\right) \frac{1}{1+a_{2} \frac{v_{d}}{d}}
$$

In the above $d$ is the shearband thickness, $x_{d}$ the slide displacement and $v_{d}$ the slide velocity, so that the (thickness-dependent) shear strain is $\gamma \approx \frac{x_{d}}{d}$ and its rate $\dot{\gamma} \approx \frac{v_{d}}{d}$. The limiting values $\mu_{r s}$ and $\mu_{r d}$ are respectively the static and dynamical residual friction coefficients, while $\mu_{p}$ is the initial value of friction coefficient and $a_{1}=0.114, a_{2}=0.103$ are numerical factors defining how quickly the static and dynamic coefficients respectively decrease with displacement and velocity. The material-friction softening critical state parameter $\hat{M}$ can be written as [32]:

$$
\hat{M}=\sqrt{3} \sin [\arctan (\hat{\mu})]
$$

Furthermore, an additional mechanism of thermal-friction softening may be implemented, by employing the linear law (2). The final expression for the critical state parameter is the result of superposition of the frictional displacement-, velocityand thermal-softening effects, so that parameter $M$ starts from a reference value and decreases towards zero according to expression (19).

\section{Acknowledgments}

We gratefully acknowledge the support of the UK's Engineering and Physical Sciences Research Council (EPSRC), project "The role of frictional heating in the development of catastrophic landslides", grant number EP/C520556/1.

The support of the EU Socrates/Erasmus program is also acknowledged.

This paper is dedicated in memoriam of Professor Ioannis Vardoulakis, as he has provided the inspiration for a lot of the work. 


\section{References}

1. Habib, P., Production of gaseous pore pressure during rock slides, Rock Mechanics and Rock Engineering, 1975; 7, 193-197.

2. Anderson, D. L., An earthquake induced heat mechanism to explain the loss of strength of large rock and earth slides, paper presented at International conference on engineering for protection from natural disasters, Bangkok 1980.

3. Voight, B., and C. Faust, Frictional Heat and Strength Loss in Some Rapid Landslides, Geotechnique 1982; 32, 43-54.

4. Hueckel, T., and R. Pellegrini, Thermoplastic modelling of undrained failure of saturated clay due to heating, Soils and Foundations 1991; 31, 1-16.

5. Modaressi, H., and L. Laloui, A thermo-viscoplastic constitutive model for clays, International Journal for Numerical and Analytical Methods in Geomechanics 1997; 21, 313-335.

6. Hueckel, T., and G. Baldi, Thermoplasticity of Saturated Clays - Experimental Constitutive Study, Journal of Geotechnical Engineering-Asce, 1990; 116, 1778-1796.

7. Laloui, L., and C. Cekerevac, Thermo-plasticity of clays: An isotropic yield mechanism, Computers and Geotechnics 2003; 30, 649-660.

8. Laloui, L., Thermo-mechanical behaviour of soils, Environmental Geomechanics $2001 ; \mathbf{5}, 809-843$.

9. Laloui, L., C. Cekerevac, and B. Francois, Constitutive modelling of the thermo-plastic behaviour of soils, Revue Europeenne de genie civil 2005; 9, 635-650.

10. Chang, K. J., A. Taboada, and Y. C. Chan, Geological and morphological study of the Jiufengershan landslide triggered by the Chi-Chi Taiwan earthquake, Geomorphology 2005; 71, 293-309.

11. Vardoulakis, I., Catastrophic landslides due to frictional heating of the failure plane, Mechanics of Cohesive-Frictional Materials 2000; 5, 443-467.

12. Vardoulakis, I., Dynamic thermo-poro-mechanical analysis of catastrophic landslides, Geotechnique 2002; 52, 157-171.

13. Sulem, J., P. Lazar, and I. Vardoulakis, Thermo-poro-mechanical properties of clayey gouge and application to rapid fault shearing, International Journal for Numerical and Analytical Methods in Geomechanics 2007; 31, 523-540.

14. Campanella, R. G., and J. K. Mitchell, Influence of temperature variations on soil behavior, University of California, Institute of Transportation and Traffic Engineering, Soil Mechanics and Bituminous Materials Research Laboratory, Berkeley, 1968.

15. Hueckel, T., and M. Borsetto, Thermoplasticity of Saturated Soils and Shales Constitutive-Equations, Journal of Geotechnical Engineering-Asce 1990; 116, 1765-1777.

16. Sultan, N., P. Delage, and Y. J. Cui, Temperature effects on the volume change behaviour of Boom clay, Engineering Geology 2002: 64, 135-145.

17. Cui, Y. J., N. Sultan, and P. Delage, A thermomechanical model for saturated clays, Can. Geotech. J. 2000; 37, 607-620.

18. Schofield, A. N., and C. P. Wroth, Critical State Soil Mechanics, McGraw Hill, London, 1968. 
19. Muir Wood, D., Soil behaviour and critical state soil mechanics, Cambridge University Press, New York, 1990.

20. Roscoe, K., and J. Burland, On generalized stress strain behaviour of wet clay, Cambridge University Press, Cambridge (UK), 1968.

21. Marques, M. E. S., S. Leroueil, et al., Viscous behaviour of St-Roch-del'Achigan clay, Quebec. Canadian Geotechnical Journal 2004, 41(1): 25-38.

22. Rice, J. R., Heating and weakening of faults during earthquake slip, J. Geophy. Res., B, Solid Earth 2006; 111, B05311, doi:10.129/2005JB004006.

23. Wibberley, C. A. J., and T. Shimamoto, Earthquake slip weakening and asperities explained by thermal pressurization, Nature 2005; 436, 689-692.

24. Sultan, N., Etude du comportement thermo-mèchanique de l'argile de Boom: expériences et modélisation, Ph.D. thesis, ENPC, Paris, 1997.

25. Ghabezloo, S., and J. Sulem, Stress dependent thermal pressurization of a fluid-saturated rock, Rock Mechanics and Rock Engineering 2008; 42, 1-24, doi: 10.1007/s00603-008-0165-z.

26. Baldi, G., T. Hueckel, and R. Pellegrini, Thermal Volume Changes of the Mineral Water-System in Low-Porosity Clay Soils, Can. Geotech. J. 1988; 25, 807-825.

27. Baldi, G., T. Hueckel, A. Peano, and R. Pellegrini, Developments in modelling of thermo-hydro-geomechanical behaviour of Boom clay and clay-based buffer materials, Report EUR 13365, Commission of the European Communities, Nuclear science and technology, 1991.

28. Mühlhaus, H. B., and I. Vardoulakis, The Thickness of Shear Bands in Antigranular-Materials, Geotechnique 1987; 37, 271-283.

29. Vardoulakis, I., Thermo-poro-mechanical analysis of rapid fault deformation, paper presented at International Conference on Micromechanics of Granular Media, Rotterdam: Balkema, Sendai, Japan, 2001.

30. Skempton, A. W., Residual Strength of Clays in Landslides, Folded Strata and the Laboratory, Geotechnique 1985; 35, 3-18.

31. Tika, T. E., and J. N. Hutchinson, Ring shear tests on soil from the Vaiont landslide slip surface, Geotechnique 1985; 49, 59-74.

32. Cecinato, F., The Role of Frictional Heating in the Development of Catastrophic Landslides, Ph.D. thesis, 240 pp, University of Southampton, 2009.

33. Delage, P., N. Sultan, and Y. J. Cui, On the thermal consolidation of Boom clay, Can. Geotech. J. 2000; 37, 343-354.

34. Habibagahi, K., Temperature effect and the concept of effective void ratio, Indian Geotechnical Journal 1977; 1, 14-34.

35. Towhata, I., P. Kuntiwattanakul, I. Seko, and K. Ohishi, Discussion on volume change of clays induced by heating as observed in consolidation tests (Towhata and al. 1993), Soils and Foundations 1995; 35, 124-127.

36. Bishop, A. W., The Use of the Slip Circle in the Stability Analysis of Slopes, Geotechnique 1955; 5, 7-17.

37. Taylor, D. W., Fundamentals of soil mechanics, J. Wiley, New York, 1948.

38. Hendron, A. J., and F. D. Patton, The Vaiont slide, a geotehnical analysis based on new geologic observations of the failure surface, technical report, Department of the Army US Corps of Engineers, Washington, DC 1985.

39. Muller, L., The rock slide in the Vaiont valley, Felsmech. Ingenieurgeol. $1964 ; 2,148-212$. 
40. De Blasio, F. V., and A. Elverhoi, A model for frictional melt production beneath large rock avalanches, J. Geophys. Res. - Ea Sur. 2008; 113(F2), doi:10.1029/2007jf000867.

41. Mase, G. E., Schaum's outline of theory and problems of continuum mechanics, McGraw-Hill, New York, 1970.

42. Sloan, S. W., A. J. Abbo, and D. C. Sheng, Refined explicit integration of elastoplastic models with automatic error control, Engineering Computations 2001; 18, 121-154.

43. Potts, D. M., and L. Zdravkovic, Finite element analysis in geotechnical engineering : theory, Telford ; Distributed by ASCE Press, London; Reston, VA, 1999.

44. Cecinato, F., A. Zervos, E. Veveakis, and I. Vardoulakis, Numerical modelling of the thermo-mechanical behaviour of soils in catastrophic landslides, in Landslides and Engineered Slopes, edited by Z. Chen, et al., pp. 615-621, Taylor and Francis, London, 2008.

\section{Figure captions}

Figure 1. Qualitative shape of thermo-plastic yield locus, demonstrating temperature dependence of the preconsolidation stress and thermal-friction softening.

Figure 2. Scheme of the shearband and the assumed linear velocity profile, with axis reference system. The out-of-plane direction is $y$.

Figure 3. Sample effective stress path of material points within the shearband.

Figure 4. Infinite slope geometry. The shearband (shaded) has negligible thickness compared to that of the overburden, i.e. $H \gg d$. The slope inclination with respect to horizontal is $\beta$.

Figure 5. Finite difference grid showing the domain of integration. The shearband is a strain localization zone of thickness $d$, embedded in an otherwise homogeneous soil layer of total thickness $10 \mathrm{~d}$. The soil below the shearband is still, while the soil at the top of the shearband moves at the velocity $v_{\mathrm{d}}$, characteristic of the landslide overburden.

Figure 6. Calculation of pressurization coefficient $\lambda_{m}$ as a function of temperature, for four different values of the thermal softening parameter $\gamma$.

Figure 7. Temperature isochrones within the shearband and its surroundings, for the case of thermal-only friction softening. The shearband area, where strain localization takes place, is shaded.

Figure 8. Pore pressure isochrones within the shearband and its surroundings, for the case of thermal-only friction softening. The shearband area, where strain localization takes place, is shaded. 
Figure 9. Slide velocity profile for the case of TFS (dashed line) and the case of FFS (solid line).

Figure 10. Slide displacement profile for the case of TFS (dashed line) and the case of FFS (solid line).

Figure 11. Temperature isochrones within the shearband and its surroundings, for the case of FFS. The shearband area, where strain localization takes place, is shaded.

Figure 12. Pore pressure isochrones within the shearband and its surroundings, for the case of FFS. The shearband area, where strain localization takes place, is shaded.

Figure 13. Slide velocity profile for the case of no friction softening, for a 60 seconds time window.

Figure 14. Sensitivity study on the effect of thermal pressurization on the slide velocity by varying the overburden thickness $H$, with an infinite slope assumption.

\section{Notation}

$\begin{array}{cl}a_{1} & \text { rate of static friction softening. } \\ a_{2} & \text { rate of dynamic friction softening. } \\ c & \text { compressibility of soil, } \mathrm{MPa}^{-1} . \\ C_{f} & \text { thermal constant, } \mathrm{MPa} /{ }^{\circ} \mathrm{C} . \\ \mathrm{CS} & \text { critical state. } \\ c_{v} & \text { consolidation coefficient, } \mathrm{m}^{2} / \mathrm{s} . \\ d & \text { shearband thickness, } \mathrm{m} . \\ D & \text { dissipation, } \mathrm{MPa} / \mathrm{s} . \\ D_{i} & \text { temperature-dependent thermal diffusivity, } \mathrm{MPa} / \mathrm{s} . \\ e & \text { void ratio. } \\ \text { FFS } & \text { full friction softening. } \\ F_{i} & \text { heat equation (non-constant) coefficient, }{ }^{\circ} \mathrm{C} . \\ G & \text { shear modulus, MPa. } \\ \tilde{g} & \text { thermal friction sensitivity. } \\ H & \text { depth of rupture surface (slide thickness), m. } \\ I_{p} & \text { polar moment of inertia, } \mathrm{m}^{4} .\end{array}$




\begin{tabular}{|c|c|}
\hline$J$ & stress deviator, $\mathrm{MPa}$. \\
\hline$K$ & bulk modulus, $\mathrm{MPa}$. \\
\hline$k_{\mathrm{m}}$ & thermal diffusivity, $\mathrm{m}^{2} / \mathrm{s}$. \\
\hline$k_{w}$ & soil permeability, m/s. \\
\hline$M$ & critical state parameter. \\
\hline$n$ & porosity. \\
\hline NCL & normal-consolidation line. \\
\hline NTS & no thermal-friction softening. \\
\hline OCR & over-consolidation ratio. \\
\hline$p^{\prime}$ & mean effective stress, $\mathrm{MPa}$. \\
\hline$q$ & deviatoric stress, $\mathrm{MPa}$. \\
\hline$R$ & radius of failure circle, $\mathrm{m}$. \\
\hline$t$ & time, s. \\
\hline $\mathrm{T}$ & net driving moment \\
\hline TFS & thermal-friction softening. \\
\hline$u$ & excess pore pressure, $\mathrm{MPa}$. \\
\hline URL & unloading-reloading line. \\
\hline$v_{d}$ & landslide velocity, $\mathrm{m} / \mathrm{s}$. \\
\hline $\mathrm{v}$ & specific volume. \\
\hline$\beta_{\mathrm{s}}$ & thermo-elastic expansion coefficient, ${ }^{\circ} \mathrm{C}^{-1}$. \\
\hline$\alpha_{c}^{t p}$ & thermo-plastic contraction coefficient ${ }^{\circ} \mathrm{C}^{-1}$. \\
\hline$\beta$ & slope angle. \\
\hline$\gamma$ & rate of thermal softening. \\
\hline$\gamma_{s}$ & unit weight of soil, $\mathrm{N} / \mathrm{m}^{3}$. \\
\hline$\gamma_{w}$ & unit weight of water, $\mathrm{N} / \mathrm{m}^{3}$. \\
\hline$\Gamma$ & specific volume intercept of critical state line. \\
\hline$\varepsilon_{v}^{p}$ & volumetric plastic strain \\
\hline$\theta$ & temperature, ${ }^{\circ} \mathrm{C}$. \\
\hline$\kappa$ & slope of unloading-reloading line. \\
\hline$\lambda$ & slope of isotropic normal compression line. \\
\hline$\lambda_{m}$ & pore pressure coefficient, $\mathrm{MPa} /{ }^{\circ} \mathrm{C}$. \\
\hline$v$ & Poisson's ratio. \\
\hline
\end{tabular}


soil density, $\mathrm{Kg} / \mathrm{m}^{3}$.

apparent isotropic preconsolidation stress, $\mathrm{MPa}$. critical state friction angle.

constant with dimensions of angular velocity, $\mathrm{s}^{-1}$. 
Tables 
Table 1. Material and geometrical parameters for 'Section 5' of the Vajont slide, in line with Vardoulakis [12].

\begin{tabular}{|c|c|c|c|}
\hline Parameter & Symbol & Value & Units \\
\hline Soil density & $\rho$ & $2.44 * 10^{3}$ & $\mathrm{Kg} / \mathrm{m}^{3}$ \\
\hline Unit weight of the soil & $\gamma_{s}$ & $23.89 * 10^{3}$ & $\mathrm{~N} / \mathrm{m}^{3}$ \\
\hline Unit weight of water & $\gamma_{w}$ & $9.81 * 10^{3}$ & $\mathrm{~N} / \mathrm{m}^{3}$ \\
\hline Thermal constant & $C_{f}$ & 2.84 & $\mathrm{MPa} /{ }^{\circ} \mathrm{C}$ \\
\hline Radius of the failure circle & $R$ & 1493 & $\mathrm{~m}$ \\
\hline Radius of the "friction circle" & $R_{D}$ & 594.8 & $\mathrm{~m}$ \\
\hline Polar moment of inertia of slide & $I_{p}$ & 0.511 & $\mathrm{~km}^{4}$ \\
\hline Resultant driving moment & $T_{D}$ & 2344.3 & $\mathrm{GNm} / \mathrm{m}$ \\
\hline Slide geometry parameter & $\omega_{0}$ & $8.1 * 10^{-2}$ & $\mathrm{~s}^{-1}$ \\
\hline Shearband thickness & $d$ & $1.4 * 10^{-3}$ & $\mathrm{~m}$ \\
\hline Soil permeability & $k_{w}$ & $10^{-11}$ & $\mathrm{~m} / \mathrm{s}$ \\
\hline Reference temperature & $\theta_{0}$ & 12 & ${ }^{\circ} \mathrm{C}$ \\
\hline Soil thermal diffusivity coefficient & $k_{m}$ & $1.45 * 10^{-7}$ & $\mathrm{~m}^{2} / \mathrm{s}$ \\
\hline Slope of URL of clay & $\kappa$ & $4.3 * 10^{-2}$ & ----- \\
\hline Slope of NCL of clay & $\lambda$ & 0.16 & ----- \\
\hline Specific volume intercept of clay & $\Gamma$ & 2.8 & $\begin{array}{ll}---- \\
--1\end{array}$ \\
\hline Initial (mean) normal effective stress & $\sigma_{n}^{\prime}$ & 2.38 & $\mathrm{MPa}$ \\
\hline Soil (drained) Poisson's ratio & $v$ & 0.2 & ----- \\
\hline Compressibility of water & $c_{w}$ & $4.93 * 10^{-4}$ & $\mathrm{MPa}^{-1}$ \\
\hline Incipient failure friction angle & $\varphi_{p}^{\prime}$ & 22.3 & $\circ$ \\
\hline Static residual friction angle & $\varphi_{r s}^{\prime}$ & 10.2 & $\circ$ \\
\hline Dynamic residual friction angle & $\varphi_{r d}^{\prime}$ & 4.4 & $\circ$ \\
\hline
\end{tabular}


Table 2. Mid-range parameter values chosen for the planar sliding analysis.

\begin{tabular}{|l|l|l|l|}
\hline Parameter & Symbol & Value & Units \\
\hline Unit weight of water & $\gamma_{w}$ & $9.81 * 10^{3}$ & $\mathrm{~N} / \mathrm{m}^{3}$ \\
\hline Unit weight of the overburden & $\gamma_{s}$ & $24.5^{*} 10^{3}$ & $\mathrm{~N} / \mathrm{m}^{3}$ \\
\hline Slope inclination & $\beta$ & 20 & degrees \\
\hline Shearband thickness & $d$ & $1 * 10^{-2}$ & $\mathrm{~m}$ \\
\hline Slope of URL of clay & $\kappa$ & $4.5^{*} 10^{-2}$ & ----- \\
\hline Slope of NCL of clay & $\lambda$ & 0.17 & ----- \\
\hline Specific volume intercept of clay & $\Gamma$ & 3.2 & ----- \\
\hline Soil (drained) Poisson's ratio & $v$ & 0.3 & ----- \\
\hline Compressibility of water & $c_{w}$ & $4.93 * 10^{-4}$ & $\mathrm{MPa}{ }^{-1}$ \\
\hline Reference temperature & $\theta_{r e f}$ & 20 & ${ }^{\circ} \mathrm{C}$ \\
\hline Soil thermal diffusivity coefficient & $k_{m}$ & $1.45^{*} 10^{-7}$ & $\mathrm{~m}^{2} / \mathrm{s}$ \\
\hline Thermo-elastic expansion coefficient & $\beta_{s}$ & $7.41^{*} 10^{-5}$ & ${ }^{\circ} \mathrm{C}^{-1}$ \\
\hline Thermal constant & $C_{f}$ & 2.84 & $\mathrm{Mpa} /{ }^{\circ} \mathrm{C}$ \\
\hline Soil permeability & $k_{w}$ & $10^{-11}$ & $\mathrm{~m} / \mathrm{s}$ \\
\hline Thermal softening parameter & $\gamma$ & $10^{-2}$ & ----- \\
\hline Friction angle at CS & $\varphi_{c s}^{\prime}$ & 27.4 & $\mathrm{degrees}$ \\
\hline
\end{tabular}

